\title{
The Separation Anxiety Daily Diary: Child Version: Feasibility and Psychometric Properties
}

\author{
Jennifer L. Allen • Judith Blatter-Meunier • Antonia Ursprung • \\ Silvia Schneider
}

Published online: 8 July 2010

(C) Springer Science+Business Media, LLC 2010

\begin{abstract}
This report describes the feasibility and psychometric properties of the child version of the Separation Anxiety Daily Diary (SADD-C) in 125 children (ages 714 years) from German-speaking areas of Switzerland. Children with separation anxiety disorder (SAD; $n=58)$, "other" anxiety disorders $(n=36)$, and healthy controls $(n=31)$ recorded the frequency of parent-child separations, along with associated anxiety, thoughts, reactions and subsequent parental responses. Compliance rates were modest, consistent with past research on self-report diaries with anxious children. The SADD-C was better at discriminating children with SAD from controls than "other anxious" children. The SADD-C demonstrated good convergent validity with maternal and child selfreported anxiety (Revised Child Manifest Anxiety Scale, Separation Anxiety Inventory) and perceived quality of life (Inventory for Quality of Life in Children and Adolescents). Results provide support for the SADD-C as an acceptable and valid method of assessing child symptoms and parent behavior on separation. Findings are discussed with regard to the clinical utility of the SADD-C and strategies to improve compliance.
\end{abstract}

Keywords Separation anxiety disorder · Assessment · Diaries · Self-monitoring · Children

J. L. Allen · J. Blatter-Meunier · A. Ursprung · S. Schneider ( $\square)$

Department of Psychology, University of Basel, Missionsstrasse 64a, Basel 4055, Switzerland e-mail: silvia.schneider@unibas.ch

\section{J. L. Allen}

e-mail: jennifer.allen@kcl.ac.uk

J. Blatter-Meunier

e-mail: judith.blatter@unibas.ch
A. Ursprung
e-mail: antonia.ursprung@kispi.uzh.ch

J. L. Allen

Institute of Psychiatry, Kings College London, London, UK 


\section{Introduction}

Children with separation anxiety disorder (SAD) experience developmentally inappropriate and excessive anxiety when separated from home or attachment figures. Children with SAD worry that separation will result in harm to themselves (e.g., being lost, kidnapped) or caregivers (e.g., accident) [1]. They may therefore avoid sleeping alone, attending school, or visiting friends. Children with SAD may also exhibit anxious behaviors such as crying, throwing tantrums or clinging to parents when separation occurs or is anticipated. While for some children separation anxiety is mild and transient, for others the distress and avoidance associated with this disorder may cause a significant decrease in quality of life [2].

Current measures of SAD symptoms tend to rely on parent-report given that this disorder may begin from a very young age. The average age of first onset for SAD is 8 years [3], with a decline in symptoms from middle childhood (8-12 years) to adolescence [4]. Although the prevalence of SAD remits with age, $[4,5]$ for many children it may appear/ persist in middle childhood or adolescence [2]. Thus, while paper-and-pencil self-report measures are not suitable for very young children with SAD, there remains a substantial number for whom they present a feasible option. Child-report measures may also provide otherwise unobtainable information given that central features of anxiety are covert (e.g., anxious thoughts) or relate to subjective experience (e.g., intensity of anxiety). The low agreement for parent and child report of separation anxiety [6] also suggests that obtaining child views on their difficulties could yield unique or additional information to inform treatment planning and ongoing assessment.

The few child-report measures specifically designed to assess separation anxiety provide little evidence for their psychometric properties in clinical samples. Several anxiety symptom questionnaires include a separation anxiety scale and have provided evidence for their reliability and validity, such as the Screen for Child Related Anxiety Disorders (SCARED) [7], Spence Child Anxiety Scale (SCAS) [8], and the Multidimensional Anxiety Scale for Children (MASC) [9]. Questionnaires offer clear benefits, including the provision of normative data and efficiency of scoring and administration. One drawback, however, is their limited ability to identify patterns of child and parent behavior that may serve to promote anxiety. Self-monitoring techniques such as diaries are viewed by many as the best tool for performing a functional analysis $[10,11]$. The monitoring of anxious behaviors, along with their antecedents and consequences enables therapists to devise an effective treatment strategy.

The development of diaries for specific fears has been recommended given that providing children with an exhaustive list of potentially anxiety-provoking situations would be impractical [12]. SAD is an ideal candidate for the diary format given its specific focus on parent-child separation [11, 12]. Diaries focusing on recently observed concrete events such as parent-child separations may be easier for children to complete than questionnaires assessing symptom frequency/severity over extended time periods. A potential disadvantage of diaries relates to their feasibility, given their reliance on the recall and motivation of children for their completion. Other issues, such as the ability of child-report diaries to discriminate between the different anxiety disorders remain to be investigated. This has typically been problematic for structured diagnostic interviews [6], however child selfreport questionnaires have demonstrated satisfactory discriminant validity $[8,13]$.

Current theoretical models emphasize anxious cognitions, avoidance and parental overprotection as factors that may promote anxiety in children [14-16]. Anxious children are more likely to select threatening interpretations of ambiguous situations and avoidant responses than controls [17]. Such information processing biases in anxious children are well- 
documented, and include a tendency to shift attention toward threatening stimuli and enhanced memory for threat-related information $[18,19]$. Parents of anxious children are also more likely to reinforce their child's avoidance of situations perceived as threatening [20]. While the content-specificity of anxious cognitions in separation anxiety has been demonstrated [21], it is unknown whether it generalizes to other symptom dimensions or parental behaviour. Thus, the detailed information about symptoms displayed by children and parental responses during real-life separations gathered from diaries may deepen our understanding of SAD.

Despite the potential of daily diaries, only two studies have examined their use with anxious children. Beidel et al. [12] evaluated a daily dairy listing socio-evaluative events and potential responses in test-anxious $(n=32)$ and non-test anxious children $(n=25)$. Children completed the diary for an average of 7.9-11.5 days, with 31-39\% complying for the entire two-week period. Children within this sample who met criteria for an anxiety disorder $(n=17)$ did not differ from healthy controls on the number of anxiety-provoking events; however they reported greater distress and more negative reactions (e.g., crying, avoidance). Allen, Blatter-Meunier, Ursprung and Schneider [22] evaluated the parent version of the Separation Anxiety Daily Diary (SADD-P) in mothers of children (415 years) diagnosed with SAD $(n=96)$, "other" anxiety disorders $(n=49)$ and healthy controls $(n=43)$. Mothers completed the diary for an average of 5.5-7.2 days, with 78$91 \%$ of individual SADD-P items completed. The SADD-P showed good convergent validity with child anxiety symptom and quality of life measures. Mothers reported more anxiety-provoking separations and subsequent negative reactions for children with SAD than healthy controls. The frequency of anxiety-provoking separations also differentiated children with SAD from "other anxious" children. Thus, there is some initial support for the feasibility and validity of daily diaries in the assessment of anxiety in children.

The present study is the first to evaluate compliance with the child version of Separation Anxiety Daily Diary (SADD-C) and its psychometric properties. The sample overlaps with previous research on maternal report on the parent version of SADD in children aged 414 years [22]; however the present study focuses on the development and validation of the child version of the SADD in children aged 8 years and older. The SADD-C assesses whether parent-child separations trigger anxiety in children along with anxious thoughts and reactions. Parental avoidance of situations (i.e., separation) that may provoke anxiety in their child is also assessed given theoretical and empirical links with child anxiety [23]. We investigated the ability of the SADD-C to effectively discriminate separation anxious children from children with other anxiety disorders and healthy control children. Children with SAD are predicted to report significantly more anxiety-provoking separations, increased anxiety, more anxious thoughts and negative reactions, along with more frequent parental avoidance of separation than the two comparison samples. The convergent validity of the SADD-C was examined, with significant associations predicted between increased child anxiety symptoms, poorer quality of life and the abovementioned SADD-C variables.

\section{Method}

\section{Participants}

The separation anxiety sample comprised 58 children with SAD aged 7-14 years and their mothers. Children met DSM-IV criteria for a principal diagnosis of SAD based on a structured diagnostic interview (see below). More than half of the SAD sample $(n=35$, $60 \%$ ) met criteria for a comorbid diagnosis, including other anxiety disorders $(n=28$, 
48\%), externalizing disorders $(n=6,10 \%)$, and "other" disorders such as Primary Insomnia $(n=7,12 \%)$, Sleep disorders $(n=3,5 \%)$, Tic disorders $(n=3,5 \%)$, Tourette's disorder $(n=1,2 \%)$ and Major Depression $(n=1,2 \%)$. All mothers were identified as the primary attachment figure involved in the child's separation anxiety diagnosis.

The other anxious sample consisted of 36 children (aged 8-14 years) with an anxiety disorder and their mothers. Children were excluded from this sample if they met DSM-IV criteria for SAD as a principal or comorbid diagnosis. Principal diagnoses were as follows: Social Phobia $(n=16,44 \%)$, Specific Phobia $(n=11,31 \%)$, Generalized Anxiety Disorder $(n=4,11 \%)$, Obsessive Compulsive Disorder $(n=2,6 \%)$, Panic Disorder with Agoraphobia $(n=2,6 \%)$, Agoraphobia without Panic Disorder $(n=1,3 \%)$. Comorbid diagnoses included anxiety disorders $(n=10,28 \%)$, externalizing disorders $(n=4,11 \%)$, mood disorders $(n=4,11 \%)$ and "other" disorders $(n=7,19 \%)$, including Primary Insomnia and Tic disorders. Participants in the two clinical samples were recruited through outpatient university and community mental health clinics in Basel and Zurich, Switzerland and advertisements or local media. No specific incentives were offered to the two clinical samples for their participation, rather the diaries formed part of a broader assessment protocol completed prior to subsidized treatment.

The healthy control sample consisted of 31 children aged 8-14 years and their mothers recruited through advertisements and parent information evenings. Children were excluded from this sample if they met criteria for any DSM-IV diagnoses. Children were given a small gift as thanks for their participation, while mothers received a payment of 20 Swiss Francs (14 Euros per h).

\section{Measures}

Diagnostic Interview for Mental Disorders in Children and Youth for DSM-IV-TR: Parent and Child Versions [translation from: Diagnostisches Interview psychischer Störungen im Kindes- und Jugendalter (Kinder-DIPS); DSM-IV-TR Version]. The Kinder-DIPS [24] are structured interviews designed to assess anxiety and common comorbid disorders in children and adolescents according to criteria set out in DSM-IV-TR [25]. The KinderDIPS provides combined diagnoses on the basis of parent and child report of symptoms and associated impairment. Combined diagnoses and severity (impairment) ratings were provided by qualified clinical psychologists or graduate students following separate parent and child interviews. Clinicians had all previously received extensive training, involving completion of coursework on diagnostic interviewing, practice rating audiotaped interviews, and practice administering and scoring the Kinder-DIPS under the supervision of a senior clinician. Clinicians were trained to criterion, which was agreement of all diagnoses in three out of five interviews (including agreement on primary diagnosis, additional diagnoses and lifetime diagnoses). Clinicians provide ratings of the severity of impairment associated with each diagnosis for the child on an 8-point scale from 1 (no) to 8 (very severe), with ratings $\geq 4$ signifying clinically significant impairment. Principal diagnostic status is decided on the basis of the highest overall severity rating, with comorbid diagnoses representing all other diagnoses where DSM-IV diagnostic criteria are met. The Kinder-DIPS has demonstrated moderate to good validity and retest reliability for axis I principal diagnoses (child version: $\kappa \mathrm{s}=.48-.88$, parent version: $\kappa \mathrm{s}=.74-.96$ ). Inter-rater reliability estimates are good for clinician-based diagnoses of SAD $(\kappa=.85)$, an overall diagnosis of an anxiety disorder $(\kappa=.85)$ and other axis I disorders $(\kappa \mathrm{s}=.85-.94)$ [25, $26]$. In the current sample, inter-rater reliabilities were very good for diagnoses of SAD $(\kappa=.85)$ and for an overall diagnosis of anxiety $(\kappa=.85)$. 


\section{Separation Anxiety Daily Diary: Child Version ${ }^{1}$}

The SADD-C gathers information about child symptoms and parent behaviors in separation situations (see Table 1 for SADD-C items). The structure of the SADD-C was guided by the behavioral analysis model (i.e., situation, thoughts, feelings, behaviors, consequences) and its content influenced by theoretical models outlining contributing factors to the development and maintenance of anxiety in children [14-16]. Selection of item stems for child thoughts and reactions in response to separation were based on pilot study findings. Ten children with SAD completed a structured interview concerning these factors and their most frequent responses included. Item selection was also informed by literature on the phenomenology of SAD given the small sample and preliminary nature of these results. The SADD-C is parallel to the parent version in content and structure, with the following exceptions: items assessing child thoughts replaced the SADD-P equivalents, and the instructions were re-worded and simplified for children. The SADD-P has been validated in a sample overlapping with that of the current study [22], however including younger children (4 years and above).

The SADD-C begins with an overview, where children record the daily number of anxious and non-anxious separations (or attempted separations) that occur over an 8-day assessment period. More detailed information is recorded on situation sheets, contained overleaf from the overview. Situation sheet items include the nature (i.e., if it is anxietyprovoking for the child) and type of separation situation, as well as the child's separationrelated anxiety level, anxious thoughts, reactions and subsequent parent reactions. Children place a cross next to the listed pre-set options for each item that reflects their experience. An "other" option is included for each item in the event that pre-set options fail to accurately describe their experience. Pre-set options for the nature and type of separation are mutually exclusive, while multiple responses are permitted for the remaining items. Separation-related anxiety is rated on a 4-point scale from 1 (very calm) to 4 (very anxious). For each reported separation, child reactions are coded 1 if any positive/neutral reactions are selected ( 2 items: accepted it/felt happy) and coded -1 if any of the remaining negative reactions are selected ( 6 items). A score of -1 is awarded only if at least one negative reaction and no neutral/positive reactions are selected; conversely a score of 1 is only awarded if at least one positive/neutral option and no negative reactions have been selected. Exceptions to the above are coded zero. Thus lower scores indicate more negative child reactions to parent-child separation.

\section{Demographics Questionnaire}

A brief background questionnaire was included to obtain mother report of child age and sex, maternal age, nationality/ethnicity, monthly income and maternal relationship status (whether mothers were married/in a defacto relationship vs. single).

\section{Revised Children's Manifest Anxiety Scale: Child and Parent Versions [27, 28]}

The RCMAS-C/P assess anxiety symptoms in children. Both child and parent versions have shown good validity in German-speaking samples [29]. Cronbach's alphas were .88 and .79 for the child and parent versions, respectively.

\footnotetext{
${ }^{1}$ Copies of the SADD-C/P in German or English can be obtained from the last author.
} 
Table 1 List of SADD-C items

Overview

1. Total number of anxious separations per day

2. Total number of non-anxious separations per day

Situation sheet

1. Anxious or non-anxiety provoking separation

2. Type of separation

i. Parent(s) intended to go out without child

ii. Child was supposed to go out without parent(s)

iii. Child was supposed to go to sleep in own bed or bedroom

3. Anxiety rating ( $0-4$ scale)

4. Thoughts:

i. Something bad will happen to me

ii. Something bad will happen to my parents

iii. Someone will kidnap me

iv. I will have an accident

v. My parents will have an accident

5. Child reactions

i. Cried

ii. Clung to parent

iii. Screamed

iv. Complained

v. Accepted it

vi. Felt sad

vii. Threw a tantrum

viii. Felt happy

6. Parent reactions

i. Parent stayed at home with their child

ii. Parent went out without their child

iii. Parent insisted that their child face the situation

Separation Anxiety Inventory for Children: Child and Parent Versions [30]

The SAI-C/P is a 12-item measure of the degree of child distress and avoidance of separation situations. Responses are recorded on a 5-point scale from 0 (never) to 4 (always). Child and parent versions have shown good retest reliability $(r \mathrm{~s}=.84, .66)$ and moderate agreement $(r=.47)$. Alphas were .86 and .91 , respectively.

Inventory for the Assessment of Quality of Life in Children and Adolescents: Child and Parent Versions [31, 32]

The ILC-C/P each consist of 7 items designed to assess perceived child quality of life. Responses are recorded on a 5-point scale ranging from 1 (very good) to 5 (very bad). Both child and parent versions can differentiate between children attending in- and outpatient psychiatric clinics $[32,33]$. Alphas were .77 and .81 for ILC-C/P total scores. 


\section{Procedures}

The present study was conducted at our university outpatient clinic from December 2004 to August 2008, and was reviewed and approved by the local ethics committee for medical research. After obtaining the informed consent of mothers and children, families were mailed questionnaires, which were returned at the Kinder-DIPS assessment. Mothers and children were introduced to the SADD following Kinder-DIPS administration. The therapist worked through one example separation with mother and child separately to demonstrate correct completion. Children were not required to complete the SADD-C if they were unable to do so independently ( $n=2$, SAD sample). Participants were asked to complete the overview and one situation sheet for every anxious separation encountered over the entire 8-day assessment period. Recording of only one separation each day that did not trigger anxiety for the child was required to reduce participant burden. Mothers and children were asked to complete the SADD separately at home for the same 8 consecutive days. Diaries formed part of a research protocol completed prior to participation in a randomized controlled trial (RCT). Participants in the SAD sample were told that the information gathered from the SADD-C would assist in treatment planning and evaluation. Four children did not complete the SADD-C or questionnaires ( $\mathrm{SAD}=3$, other anxious $=1$ ); this data is therefore excluded from relevant analyses.

\section{Results}

\section{Sample Characteristics}

The majority of children (88\%) came from two-parent families. All mothers and children were white and German-speaking, with most participants identified as Swiss (76\%), followed by "other" European (24\%). Examination of monthly household income indicated a predominantly middle to upper middle class sample (see Table 2). Groups were compared on demographic data using chi-squares and between-subjects one-way analyses of variance (ANOVA) with Bonferroni adjustments for post-hoc comparisons. Critical alpha was set at .017 for all analyses given three post-hoc between-subjects comparisons (SAD vs. other anxious, SAD vs. healthy controls, and other anxious vs. controls). There were no significant group differences for maternal or child age, $F(2,124)=.34, F(2,120)=2.43$, $p s>.017$. Chi-square analyses did not detect any group differences on child sex, $\chi^{2}(2$, $125)=.83, p>.017$; or whether children were of Swiss or other European nationality, $\chi^{2}$ $(2,123)=1.79, p>.017$. More mothers in the healthy control sample were single than mothers in the SAD or other anxious samples, $\chi^{2}(2,122)=8.28, p=.016$. The mean severity rating for principal diagnoses was $5.78(\mathrm{SD}=.96)$ for the SAD sample and 5.78 $(\mathrm{SD}=.80)$ for the other anxious sample, with no significant difference between groups; $t(92)=-.010, p>.05$.

\section{Compliance}

Thirty-two children $(26 \%$; $\mathrm{SAD}=16$, other anxious $=13$, healthy control $=3)$ did not complete any part of the SADD-C, while an additional two children in the SAD sample completed the overview section only. Non-completers and completers did not differ on 
Table 2 Demographic characteristics

\begin{tabular}{llll}
\hline Demographic variable & $\begin{array}{c}\text { SAD } \\
n=58\end{array}$ & $\begin{array}{c}\text { Other anxious } \\
n=36\end{array}$ & $\begin{array}{l}\text { Healthy control } \\
n=31\end{array}$ \\
\hline Child sex, \% female & 50 & 58 & 48 \\
Child age, $M$ (SD) years & $10.1(1.8)$ & $10.3(1.6)$ & $10.4(1.8)$ \\
Maternal age, $M$ (SD) years & $42.2(4.9)$ & $40.8(4.4)$ & $43.3(4.1)$ \\
Swiss nationality, \% & 77 & 69 & 83 \\
Mother married/partnered, \% & 93 & 92 & 72 \\
Monthly income, $\%$ & & & 3 \\
Less than 1,400 & 4 & 6 & 16 \\
1,400-2,800 & 29 & 22 & 45 \\
2,801-5,600 & 47 & 50 & 36 \\
More than 5,600 & 20 & 22 & 3 \\
\hline
\end{tabular}

Monthly income converted from Swiss Francs to Euros

socio-demographic variables, ${ }^{2}$ with the exception that "other" European children $(93 \%)$ were more likely to complete the SADD-C than Swiss children $(69 \%), \chi^{2}(1,123)=6.75$, $p=.009$. Children completed the overview for an average of 7.1 dates $(\mathrm{SD}=1.8)$ and situation sheets for an average of 5.7 dates $(\mathrm{SD}=2.6)$.

Completion rates were examined as a function of group given that the greater relevance of the diary to children with SAD might influence compliance. Groups differed on child completion rates for both the overview and situation sheets, $F(2,93)=4.527$, partial $\eta^{2}=.091, p<.017 ; F(2,93)=4.382$, partial $\eta^{2}=.089, p<.017$, respectively. Children with other anxiety disorders completed the overview and situation sheets for fewer dates than children in the SAD sample, $t(63)=2.577, \quad p<.017, \quad M \mathrm{~s}=6.13,7.38$; $t(63)=3.342, p<.017, M \mathrm{~s}=7.93,5.04$. No other group comparisons were significant $(p s>.017)$.

The percentage of anxious separations reported on the overview for which detailed sheets were completed was calculated. This allowed examination of the extent to which children complied with the instruction to complete a more detailed situation sheet for each anxious separation that occurred during the 8-day assessment period. Children who did not report any anxious separations on the overview were excluded given that no further reporting was required (SAD: $n=3$; OAD: $n=9$; HC: $n=23$ ). Completion rates were $87 \%(n=39)$ for the SAD sample, $72 \%(n=14)$ for the other anxious sample and $80 \%$ $(n=5)$ for healthy controls. The most missing data from the situation sheets ${ }^{3}$ was for child thoughts $(29 \%)$, parent reactions $(20 \%)$ and child reactions $(10 \%)$. Compliance was best for child anxiety ratings along with the nature and type of separation, with $96 \%$ or more of these items completed. No significant associations were detected between the percentage of missing data for any SADD-C items and child age, $-.10<r \mathrm{~s}<.17, p \mathrm{~s}>.05$; or sex, $-.17<r \mathrm{~s}<.01, \mathrm{ps}>.05$.

\footnotetext{
2 The first author can be contacted for the exact statistics.

${ }^{3}$ Chi-squared analyses did not detect any significant group differences on the amount of missing data for any situation sheet variables, all $p$ s $>.017$.
} 
Calculation of SADD-C Variables

The total number of anxious separations reported was summed and divided by the total number of separations (anxious and non-anxious) reported during the entire assessment period. This process yielded a proportion for anxious separations and controlled for individual differences in the number of separations reported. This proportion was then multiplied by 8 to produce the estimated frequency of anxious separations during the 8-day assessment period. Thus, a one unit increment represents one additional anxious separation during the assessment period. Only anxious separations are reported given that the conversion of both anxious and non-anxious separations to proportions would produce a double-up of results, with the proportion of non-anxious separations merely representing the inverse of the proportion of anxious separations. The remaining SADD-C items (anxious thoughts, anxiety level, child reactions and parental reinforcement of child avoidance variables) were summed and then averaged across the total number of responses provided. Table 3 displays means and standard deviations for SADD-C variables.

\section{Discriminative Validity}

Groups were compared on SADD-C variables using one-way between-subjects ANOVAs with Bonferroni adjustments for post-hoc comparisons. ${ }^{4}$ There were no group differences on child report of the total number of separations. Groups differed significantly on the frequency of anxious separations, along with child anxiety ratings, anxious thoughts and reactions. Children in the SAD and other anxious samples reported significantly more anxious separations, anxious thoughts and negative reactions to parent-child separation along with increased anxiety than healthy controls. The only variable to differentiate the SAD from the "other anxious" sample were child ratings of anxiety intensity when separation from parents occurred or was anticipated. No group differences were present on variables assessing parental reinforcement of child avoidance of separation.

\section{Convergent Validity}

The relationships between SADD-C variables and measures of child anxiety symptoms and perceived quality of life and were examined for the entire sample using Pearson correlation coefficients (Table 4). Increased symptoms of separation anxiety (SAI-C/P) and general anxiety (RCMAS-C/P) showed moderate to strong significant associations with almost all SADD-C variables, with the notable exception of those assessing parental reinforcement of child avoidance. Maternal perceptions of poor child quality of life was significantly associated with a greater frequency of anxious separations, increased child anxiety and more negative child reactions to separation. Only increased child anxiety on separation was significantly associated with child perceptions of poorer life quality.

\section{Discussion}

This study was the first to examine the psychometric properties of a child-report daily diary specifically designed to assess separation anxiety symptoms and associated parent factors.

\footnotetext{
4 All ANOVAs comparing groups on SADD-C variables were first conducted with maternal relationship status as a covariate. No between subjects main effects of maternal relationship status were significant (all $p \mathrm{~s}>.017$ ), thus ANOVAs were repeated without maternal relationship status as a covariate.
} 
Table 3 Group comparisons and means (SD) for child report on the SADD

\begin{tabular}{|c|c|c|c|c|c|c|c|c|c|c|}
\hline \multirow[t]{2}{*}{ SADD-C variables } & \multicolumn{2}{|c|}{$\begin{array}{l}\text { SAD } \\
n=58\end{array}$} & \multicolumn{2}{|c|}{$\begin{array}{l}\text { Other anxious } \\
n=36\end{array}$} & \multicolumn{2}{|c|}{$\begin{array}{l}\text { Healthy } \\
\text { control } \\
n=31\end{array}$} & \multicolumn{3}{|l|}{ Statistic } & \multirow[t]{2}{*}{ Comparison } \\
\hline & $M$ & SD & $M$ & SD & $M$ & SD & $F$ & $\eta^{2}$ & $t$ & \\
\hline Total separations & 12.90 & 5.70 & 12.96 & 10.03 & 13.71 & 6.64 & 6.145 & .003 & - & - \\
\hline $\begin{array}{l}\text { Total number of } \\
\text { anxious separations }^{\mathrm{a}}\end{array}$ & 2.99 & 2.03 & 2.01 & 2.57 & .19 & .38 & 18.224 & .291 & $\begin{array}{l}1.694 \\
7.100 \\
3.663\end{array}$ & $\begin{array}{l}\text { SAD vs. } \mathrm{OA} \\
\text { SAD vs. } \mathrm{HC}^{* *} \\
\mathrm{OA} \text { vs. } \mathrm{HC}^{*}\end{array}$ \\
\hline $\begin{array}{l}\text { Parent(s) intended to } \\
\text { go out and leave } \\
\text { child at home }\end{array}$ & .21 & .21 & .36 & .37 & .30 & .27 & 2.479 & .052 & - & - \\
\hline Child anxiety rating & 2.41 & .67 & 1.89 & .77 & 1.15 & .22 & 36.775 & .450 & $\begin{array}{l}2.884 \\
9.601 \\
4.872\end{array}$ & $\begin{array}{l}\text { SAD vs. } \mathrm{OA}^{*} \\
\text { SAD vs. } \mathrm{HC}^{* *} \\
\mathrm{OA} \text { vs. } \mathrm{HC}^{* *}\end{array}$ \\
\hline $\begin{array}{l}\text { Child anxious } \\
\text { thoughts }\end{array}$ & .87 & .91 & .54 & .81 & .17 & .38 & 6.293 & .129 & $\begin{array}{l}1.421 \\
3.597 \\
-4.872\end{array}$ & $\begin{array}{l}\text { SAD vs. } \mathrm{OA} \\
\text { SAD vs. } \mathrm{HC}^{* *} \\
\mathrm{OA} \text { vs. } \mathrm{HC}^{*}\end{array}$ \\
\hline Child reactions & .21 & .69 & .61 & .73 & .98 & .10 & 12.941 & .249 & $\begin{array}{l}2.057 \\
-5.553 \\
-2.521\end{array}$ & $\begin{array}{l}\text { SAD vs. OA } \\
\text { SAD vs. } \mathrm{HC}^{* *} \\
\text { OA vs. } \mathrm{HC}^{*}\end{array}$ \\
\hline $\begin{array}{l}\text { Parent stayed at home } \\
\text { with child }\end{array}$ & .31 & .30 & .13 & .24 & .30 & .29 & 3.466 & .075 & - & - \\
\hline
\end{tabular}

$S A D D-C$ separation anxiety daily diary-child version, $S A D$ separation anxiety disorder, $O A$ other anxious, $H C$ healthy control

$* p<.017 ; * * p<.001$

a Only anxious separations are reported given that the conversion to proportions produces a double-up of results, with the proportion of non-anxious separations representing the inverse of the proportion of anxious separations

Compliance rates were modest, but comparable to past research examining the feasibility of diaries to assess anxiety in children $[12,22]$. The SADD-C demonstrated convergent validity through significant associations between most SADD-C variables and child clinical measures. SADD-C items effectively discriminated children with SAD from healthy control children, consistent with past research [12]. However, the SADD-C appears limited in its ability to discriminate children with SAD from children with other anxiety disorders. Thus, while the addition of strategies to improve compliance are called for, the SADD-C appears to be a valid and potentially useful measure with a wide range of applications such as functional analysis, goal setting and monitoring of clinical progress.

Compliance with the SADD-C compared favorably with Beidel et al. [12], where anxious children completed a diary for an average of 7.9-11.5 days of a two-week assessment period. Children who completed the SADD-C largely adhered to the instruction to fill out a more detailed situation sheet for all anxiety-provoking separations that occurred, with compliance rates highest in the SAD sample (86\%). It must be acknowledged, however, that around a quarter of children in the current study $(N=32,26 \%)$ did not complete any part of the SADD-C. Study participants were part of an RCT involving completion of a large assessment protocol. Improved compliance may be seen in clinical practice where such heavy 
Table 4 Relationship between clinical measures and SADD-C variables

\begin{tabular}{lcccccc}
\hline SADD-C variables & ILC-P & ILC-C & RCMAS-P & RCMAS-C & SAI-P & SAI-C \\
\hline Anxious separations & $.33^{* *}$ & .18 & $.28^{*}$ & $.31^{* *}$ & $.57^{* *}$ & $.53^{* *}$ \\
Parent(s) intended to go out & .04 & .05 & .11 & -.17 & -.08 & -.14 \\
$\quad$ and leave child at home & & & & & & \\
Child anxiety rating & $.41^{* *}$ & $.25^{*}$ & $.41^{* *}$ & $.37^{* *}$ & $.63^{* *}$ & $.58^{* *}$ \\
Child anxious thoughts & $.27^{*}$ & .06 & .22 & $.31^{* *}$ & $.32^{* *}$ & $.40^{* *}$ \\
Child negative reactions & $-.30^{* *}$ & -.14 & $-.33^{* *}$ & -.19 & $-.65^{* *}$ & $-.58^{* *}$ \\
Parent(s) stayed at home with child & .07 & -.04 & .11 & .16 & .04 & .15 \\
\hline
\end{tabular}

$S A D D-C$ separation anxiety daily diary: child version, $I L C$-C/P inventory for the assessment of quality of life in children and adolescents: child and parent versions [31, 32], RCMAS-C/P revised children's manifest anxiety scale: child and parent versions [27, 28], SAI-C/P separation anxiety inventory for children: child and parent versions [30]. * $p<.05 ; * * p<.01$

assessment loads are not typically present. However, on the whole current findings suggest that strategies to improve compliance with the SADD-C are needed. These could include the use of reminders (e.g., phone calls, emails), praise and rewards by therapists and parents to motivate children to complete the diary. Electronic diaries with pre-programmed reminder "beeps" may produce greater adherence and would be suitable for older children and adolescents. Anecdotally, children with "other" anxiety disorders did not tend to view a diary focusing on anxiety around parent-child separation as relevant to their current difficulties, possibly explaining the low compliance in this group. One helpful addition to future research would be to assess barriers to diary completion. The identification of barriers would then assist in the development and implementation of strategies to address compliance. The evaluation of such strategies designed to enhance compliance are important for determining not only the feasibility of self-monitoring techniques with anxious children, but whether they can demonstrate clinical utility over more traditional assessment methods (e.g., questionnaires, interviews) that can be completed in one sitting.

Convergent validity was demonstrated through moderate to strong associations between the SADD-C and measures of anxiety symptoms and perceived child quality of life. Not surprisingly, strong associations were present between the SADD-C and a specific measure of separation anxiety (SAI), and moderate associations with a general measure of anxiety symptoms (RCMAS). These findings are consistent with maternal report on the parent version of the SADD [22]. The SADD-C performed well at differentiating children with SAD from healthy controls, with all SADD-C items assessing child symptoms discriminating between these two groups. In contrast, only ratings of anxiety intensity differentiated children with SAD from children with "other" anxiety disorders. The lack of discrimination between these two samples may reflect developmental considerations, such as psychosocial maturity which is related to the presence of SAD and GAD irrespective of child age and which has been linked to the heterotypic continuity between these two disorders [34]. Alternatively, given the wide prevalence of separation fears in community samples [2], poor discriminate validity may be due to subclinical separation anxiety symptoms in the other anxious sample. Indeed, difficulty differentiating between the specific anxiety disorders in children is a limitation shared by other forms of assessment, such as structured diagnostic interviews [6].

SADD-C items indexing parental avoidance of separation failed to differentiate anxious children from healthy controls, inconsistent with models that emphasize parental overprotection as a factor that promotes anxiety in children [14-16]. However, while 
observational and retrospective studies have consistently shown that parents of anxious children are more reinforcing of child avoidance, studies relying on parent or child current subjective report have yielded conflicting findings [35, 36]. Past research in our clinic found no evidence for a link between maternal self-reported avoidance of separation as assessed by the parent version of the SADD and separation anxiety in children [22]. It is possible that parents either do not perceive their behavior as reinforcing child avoidance or they do not report such behavior due to a self-presentation bias, thus calling the validity of parental self-report into question. Future research could compare parent self-report of avoidance of separation and reactions to child anxious behaviors with objective ratings during a behavioral observational task to resolve this issue. Alternatively, reactivity effects may have contributed to the null finding, with parents recognizing their own avoidance in response to child reactions and then altering their behavior accordingly.

Current findings indicate several limitations of the SADD-C that should be taken into account when considering its inclusion in an assessment protocol. The SADD-C is not suitable for children who have co-morbid learning difficulties and/or attention problems due to its reliance on cognitive and verbal skills. Even amongst children without such difficulties, care should be taken to ensure that they understand the task and have ample opportunity to practice completing the SADD-C under supervision prior to the commencement of self-monitoring. Self-presentation bias is also an inherent limitation for selfreport approaches, therefore parents and therapists should reinforce the child for accurate reporting on the SADD-C rather than what they would like to see recorded [10]. Given that the rate of endorsement for anxious thoughts was the lowest (61\%) of the SADD-C items, we intend to undertake further development and pilot work to ensure that listed thought options represent the experience of separation anxious children and are feasible for use with our target age group ( 8 years and above). SAD can present in children even younger than 8 years, and as such age-appropriate measures that are suitable for the child's developmental level are needed. Pictorial measures present one promising avenue for assessing separation anxiety in preschool and early school age children [37]. It should also be acknowledged that the current study sample size is relatively small for a study focussing on instrument development and validation. Further, the current sample was predominantly white, Swiss and middle class. Future studies examining the psychometric properties of the SADD-C should utilise larger samples to enable greater power to detect significant effects and that are more varied in terms of ethnicity and socioeconomic status.

The SADD-C may have benefits beyond its use as an assessment tool, such as readying the child for cognitive restructuring by laying the basis for understanding the distinction between situations, thoughts, feelings, and behaviors. The recording of a high level of anxiety could be used as a reminder for children to use strategies, such as coping self-statements or relaxation during anxiety-provoking situations [10]. Self-monitoring may produce desirable changes in behavior in its own right through increased child awareness of unhelpful thoughts and behaviors. As self-monitoring is generally just one part of a multi-component assessment and treatment package for child anxiety; as such its potential sole influence on outcome is unknown. Thus, examining whether the self-monitoring of anxiety symptoms can generate therapeutic benefits of its own accord is an interesting area for future research.

\section{Summary}

Overall, the SADD-C demonstrated acceptable compliance and good validity. This study improved on past research on child-report daily diaries through the inclusion of 
comparison samples of children with "other" anxiety disorders in addition to healthy controls. Findings provide further evidence for the feasibility and validity of daily diaries in the assessment of child anxiety. Child thoughts, anxiety about exposure to feared situations and parent reactions to child anxious behaviors are common areas targeted by family-based treatments [23]. Information gained from the SADD-C can therefore assist in the functional analysis of anxious behaviors, vital for the planning and ongoing evaluation of an individualized intervention strategy. Descriptive data gathered using daily diaries may help us gain a clearer picture of the phenomenology of SAD and thus inform theoretical models of potential maintaining factors. The SADD-C is a promising measure that, with further improvements to design and implementation, is likely to assist clinicians and researchers working with separation anxious children and their families.

Acknowledgments This study was supported by grant PP001-68701; 105314-116517/1, "Etiology and Psychological Treatment of Separation Anxiety Disorder in Childhood," awarded to Silvia Schneider by the Swiss National Science Foundation. We appreciate the participants in this study, as well as the research assistants and graduate students on the TAFF project at the University of Basel for their assistance in data collection and management. The authors would like to acknowledge the assistance of Prof. Dr. Hans Christoph Steinhausen (Child and Adolescent Psychiatry, University of Zürich). We also thank Dr. Andrea Meyer and Terry Lewin for their assistance with the statistical analyses.

\section{References}

1. Allen JL, Lavallee K, Herren C, Ruhe K, Schneider S (in press) DSM-IV criteria for childhood separation anxiety disorder: informant, age, and sex differences. J Anx Disord

2. Eisen AR, Schaefer CE (2005) Separation anxiety in children and adolescents: an individualized approach to assessment and treatment. Guilford Press, New York

3. Last CG, Perrin S, Hersen M, Kazdin AE (1992) DSM-III-R anxiety disorders in children: Sociodemographic and clinical characteristics. J Am Acad Child Adolesc Psychiatry 31:1070-1076

4. Compton S, Nelson A, March J (2000) Social phobia and separation anxiety symptoms in community and clinical samples of children and adolescents. J Am Acad Child Adolesc Psychiatry 39:1040-1046. doi:10.1097/00004583-200008000-00020

5. Costello EJ, Mustillo S, Erklani A, Keeler G, Angold A (2004) Prevalence and development of psychiatric disorders in childhood and adolescence. Archiv Gen Psych 60:837-844. doi:10.1001/archpsyc. 60.8 .837

6. Schniering CA, Hudson JL, Rapee RM (2000) Issues in the diagnosis and assessment of anxiety disorders in children and adolescents. Clin Psychol Rev 2:453-478. doi:10.1016/S0272-7358\%2899\% 2900037-9

7. Birmaher B, Khetarpul S, Brent D, Cully M, Balach L, Kaufman J, Neer SM (1997) The screen for child anxiety related emotional disorders (SCARED): scale construction and psychometric characteristics. J Am Acad Child Adol Psychiatry 36:545-553. doi:10.1097/00004583-199704000-00018

8. Spence S (1998) A measure of anxiety symptoms amongst children. Behav Res Ther 36:545-566. doi: 10.1016/S0005-7967\%2898\%2900034-5

9. March JS, Parker JD, Sullivan K, Stallings P, Conners CK (1997) The Multidimensional Anxiety Scale for Children (MASC): factor structure, reliability, and validity. J Am Acad Child Adol Psychiatry 36:554-565

10. Peterson L, Tremblay G (1999) Self-monitoring in behavioral medicine: children. Psychol Asses 11:458-465. doi:10.1037/1040-3590.11.4.458

11. Silverman WK, Ollendick TH (2005) Evidence-based assessment of anxiety and its disorders in children and adolescents. J Clin Child Adol Psychol 34:380-411. doi:10.1207/s15374424jccp3403_2

12. Beidel DC, Neal AM, Lederer AS (1991) The feasibility and validity of a daily diary for the assessment of anxiety in children. Behav Ther 22:505-517. doi:10.1016/S0005-7894\%2805\%2980342-9

13. Muris P, Dreessen L, Bögels S, Weckx M, van Melick M (2004) A questionnaire for screening a broad range of DSM-defined anxiety disorder symptoms in clinically referred children and adolescents. J Child Psychol Psych 45:813-820. doi:10.1111/j.1469-7610.2004.00274.x 
14. Chorpita BF, Barlow DH (1998) The development of anxiety: the role of control in the early environment. Psychol Bull 124:3-21. doi:10.1037/0033-2909.124.1.3

15. Hudson JL, Rapee RM (2004) From anxious temperament to disorder: an etiological model of generalized anxiety disorder. In: Heimberg RG, Turk CL, Mennin DS (eds) The etiology and development of generalised anxiety disorder. Guilford Publications, New York, pp 51-74

16. Rapee RM (2001) The development of generalized anxiety. In: Vasey MW, Dadds MR (eds) The developmental psychopathology of anxiety. Oxford University Press, Oxford, pp 481-503

17. Barrett PM, Rapee RM, Dadds MR, Ryan SM (1996) Family enhancement of cognitive style in anxious and aggressive children. J Abnorm Child Psychol 24:187-203. doi:10.1007/BF01441484

18. In-Albon T, Kossowsky J, Schneider S (2010) Vigilance and avoidance of threat in the eye movements of children with separation anxiety disorder. J Abnorm Child Psychol 38:225-235. doi:10.1007/s10802009-9359-4

19. Muris P, Field AP (2008) Distorted cognition and pathological anxiety in children and adolescents. Cog Emot 22:395-421. doi:10.1080/02699930701843450

20. Dadds MR, Barrett PM, Rapee RM, Ryan S (1996) Family process and child anxiety and aggression: an observational analysis. J Abnorm Child Psychol 24:715-734. doi:10.1007/BF01664736

21. Bögels SM, Snieder N, Kindt M (2003) Specificity of dysfunctional thinking in children with symptoms of social anxiety, separation anxiety and generalized anxiety. Behav Change 20:160-169. doi:10.1375/ bech.20.3.160.24836

22. Allen JL, Blatter-Meunier J, Urpsrung A, Schneider S (2010) Maternal daily diary report in the assessment of childhood separation anxiety. J Clin Child Adolesc Psychol 39:252-259. doi:10.1080/ 15374410903532619

23. Allen JL, Rapee RM (2005) Anxiety disorders. In: Graham P (ed) Cognitive behaviour therapy for children and families, 2nd ed. edn. Cambridge University Press, Cambridge, pp 300-319

24. Schneider S, Unnewehr S, Margraf J (2009) Diagnostisches interview psychischer Störungen im Kindes- und Jugendalter (Kinder-DIPS). Springer, Berlin

25. American Psychiatric Association (2000) Diagnostic and statistical manual of mental disorders- text revision, 4th edn. American Psychiatric Association, Washington, DC

26. Adornetto C, In-Albon T, Schneider S (2008) Diagnostik im Kindes- und Jugendalter anhand strukturierter Interviews: Anwendung und Durchführung des Kinder-DIPS. Klinische Diagnostik Evaluation 1:363-377

27. Reynolds CR, Richmond BO (1978) What I think and feel: a revised measure of children's manifest anxiety. J Abnorm Child Psychol 6:271-280. doi:10.1007/BF00919131

28. Pina AA, Silverman WK, Saavedra LM, Weems CF (2001) An analysis of the RCMAS lie scale in a clinic sample of anxious children. J Anx Disord 15:443-457. doi:10.1016/S0887-6185\%2801\%2900075-5

29. Boehnke K, Silbereisen RK, Reynolds CR, Richmond BO (1986) What I think and feel-German experience with the revised form of the Children's Manifest Anxiety Scale. Pers Individ Differ 7:553560. doi:10.1016/0191-869\%2886\%2990132-7

30. Schneider S, In-Albon T (in press) Trennungsangst Inventar-Kind/Elternversion. In Barkmann (Hrsg.) C, Schulte-Markwort M, Brähler E (eds) Diagnostik für Klinik und Praxis. Hogrefe, Göttingen

31. Mattejat F, Jungmann J, Meusers M, Moik C, Schaff C, Schmidt M-H, Scholz M, Remschmidt H (1998) Das Inventar zur Erfassung der Lebensqualität bei Kindern und Jugendlichen (ILK). Eine Pilotstudie. Zeitschrift Kinder- Jugendpsychiatrie Psychotherapie 26:174-182

32. Mattejat F, König U, Barchewitz C, Felbel D, Herpetz-Dahlmann B, Hoehne D, Janthur B et al (2005) Zur Lebensqualität von psychisch kranken Kindern und ihren Eltern. Ergebnisse der ersten multizentrischen Studie mit der Elternversion des Inventars zur Erfgassung der Lebensqualität bei Kindern und Jugendlichen (ILK). Kindheit Entwicklung 14:39-47. doi:10.1026/0942-5403.14.1.39

33. Mattejat F, Simon B, König U, Quaschner K, Barchewitz C, Felbel D, Herpertz-Dahlmann B et al (2003) Lebensqualität bei psychisch kranken Kindern und Jugendlichen: Ergebnisse der ersten multizentrischen Studie mit dem Inventar zur Erfassung der Lebensqualität bei Kindern und Jugendlichen (ILK). Zeitschrift Kinder Jugendpsychiatrie Psychotherapie 31:293-303

34. Westenberg PM, Siebelink BM, Warmenhoven NJC, Treffers PDA (1999) Separation anxiety and overanxious disorders: relations with age and level of psychosocial maturity. J Am Acad Adolesc Psychiatry 38:1000-1007. doi:10.1097/00004583-199908000-00016

35. Bögels SM, Brechman-Toussaint ML (2006) Family issues in child anxiety: attachment, family functioning, parental rearing and beliefs. Clin Psychol Rev 26:834-856. doi:10.1016/j.cpr.2005.08.001

36. Wood J, McLeod BD, Sigman M, Hwang W-C, Chu BC (2003) Parenting and childhood anxiety: theory, empirical findings, and future directions. J Child Psychol Psychiatry Allied Discip 44:134-151. doi:10.1111/1469-7610.00106

37. Dubi K, Schneider S (2009) The Picture Anxiety Test (PAT): a new pictorial assessment of anxiety symptoms in young children. J Anx Disord 23:1148-1157. doi:10.1016/j.janxdis.2009.07.020 